
$(X I A P)$

\title{
X-chromosome-linked inhibitor of apoptosis as a key factor for chemoresistance in clear cell carcinoma of the ovary
}

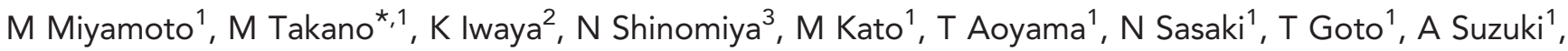 \\ $\mathrm{J} \mathrm{Hitrata}^{1}$ and K Furuya ${ }^{1}$ \\ ${ }^{1}$ Department of Obstetrics and Gynecology, National Defense Medical College, Tokorozawa, Saitama 359-8513, Japan; \\ ${ }^{2}$ Department of Basic Pathology, National Defense Medical College, Tokorozawa, Saitama 359-8513, Japan and ${ }^{3}$ Department of \\ Molecular Biology, National Defense Medical College, Tokorozawa, Saitama 359-8513, Japan
}

Background: X-chromosome-linked inhibitor of apoptosis (XIAP) is one of the anti-apoptotic proteins leading to chemoresistance in several cancers. The aim of this study is to evaluate the impact of XIAP expression upon ovarian clear cell carcinoma (CCC) that has a platinum-resistant phenotype.

Methods: Tissue microarrays made from 90 CCC patients were analysed for immunohistochemical expression levels of XIAP, c-Met, p-Akt and Bcl-XL. In addition, CCC cell lines were evaluated whether XIAP silencing could modulate sensitivity to platinum agent in vitro.

Results: High XIAP expression was observed in 30 (33\%) of 90 CCC cases, and was associated with c-Met (<0.01) and Bcl-XL $(<0.01)$ expression. Cases with high XIAP expression had lower response rate to primary platinum-based chemotherapy $(10 \%$ vs $65 \%, P=0.02)$. In stages II-IV tumours, high XIAP expression was related with worse progression-free survival (PFS, $P=0.02)$. Furthermore, high XIAP expression was identified as an independent worse prognostic factor for PFS and overall survival. Finally, downregulation of XIAP using XIAP-specific small interfering RNA increased sensitivity to cisplatin in human cancer cells derived from CCC.

Conclusions: X-chromosome-linked inhibitor of apoptosis expression was correlated with chemoresistance of primary chemotherapy, and identified as a prognostic marker for CCC. X-chromosome-linked inhibitor of apoptosis could be a candidate for new therapeutic target in CCC.

In 1973, clear cell carcinoma (CCC) of the ovary was pathologically defined by World Health Organisation as lesions characterised by clear cells growing in solid/tubular or glandular patterns as well as hobnail cells (Serov et al, 1973). Since then, many publications have identified the distinctive behaviour of CCC. First, CCC showed chemoresistance to primary chemotherapy using platinum-based therapy and combination with paclitaxel and platinum (Takano et al, 2012). Lower response was also reported in the second-line chemotherapy (Takano et al, 2008), and response duration was extremely short (Takano et al, 2013). Second, CCC had significantly worse overall survival (OS) in advanced-staged tumours (Sugiyama et al, 2000; Winter et al, 2007). New strategy is needed for further treatment of CCC.

$\mathrm{X}$-chromosome-linked inhibitor of apoptosis (XIAP) is overexpressed in several cancers including ovarian tumours (Lacasse et al, 1998; Tamm et al, 2000; Yang et al, 2003), and most reports showed that XIAP is a major contributor to chemoresistance to anticancer drugs. Caspase- 3 had an important role for cisplatininduced apoptosis in ovarian cancer cells, and cisplatin induced apoptosis through the decrease of XIAP protein levels and the 
increase of caspases-3 activity in cisplatin-sensitive ovarian serous cancer cells in a dose-dependent manner, but the effect was not evident in cisplatin-resistant cells (Asselin et al, 2001). Overexpression of XIAP by adenoviral sense XIAP complementary DNA attenuated the ability of cisplatin to induce apoptosis (Li et al, 2001). On the other hand, downregulation of XIAP using adenoviral anti-sense XIAP infection or small interfering RNA (siRNA) increased sensitivity to cisplatin in resistant serous ovarian cancer cells (Sasaki et al, 2000; Ma et al, 2009). Thus, XIAP was strongly associated with platinum resistance of ovarian cancer cells. However, these investigations were performed by ovarian serous cancer cells, and the roles of XIAP in CCC have not been analysed. Also, downregulation of c-Met decrease XIAP protein levels in ovarian cancer cells, suggesting that XIAP was regulated by hepatocyte growth factor (HGF) /c-Met pathway through Akt (Bu et al, 2011). Although c-Met has been associated with tumourigenesis in CCC (Yamamoto et al, 2011), the relationship of XIAP expression and c-Met has not been studied.

Herein, we assessed the immunoreactivities of XIAP, c-Met, $\mathrm{p}$-Akt and Bcl-XL, and analysed the correlation of XIAP expression and clinicopathologic characteristic of CCC. Moreover, we investigated whether XIAP downregulation could sensitise ovarian CCC cells to platinum agents.

\section{MATERIALS AND METHODS}

Patients and tissue microarray. Tissue blocks from 92 patients with CCC who received primary debulking surgery at National Defense Medical College hospital between 1984 and 2008 were identified. In all, 1.5-mm cores were punched from donor blocks and inserted into a recipient block. All specimens were cut into $4-\mu$ m-thick sections. Satisfactory immunohistochemical staining was obtained in 90 cases, and these cases were enrolled in this study. No patient had received neoadjuvant chemotherapy before primary surgery. The research was approved by the Ethic Committee of National Defense Medical College, Tokorozawa, Japan.

Immunochemistry and interpretation. We used mouse monoclonal antibody for MET4 (8G6 dilution 1:150; Knudsen et al, 2009), mouse monoclonal antibody for XIAP (48; dilution $1: 300$; BD Transduction, Franklin Lakes, NJ, USA), rabbit monoclonal antibody for phospho-Akt (p-Akt; Ser473; dilution 1:300; Cell Signaling Technology, Danvers, MA, USA) and rabbit monoclonal antibody for Bcl-XL (54H6; dilution 1:300; Cell Signaling Technology), respectively. Tissue microarray slides were deparaffinised in xylene and hydrated with alcohol and boiled in an autoclave at $121^{\circ} \mathrm{C}$ for $15 \mathrm{~min}$ in $0.01 \mathrm{moll}^{-1}$ citrate buffer ( $\mathrm{pH}$ 6.0) and then allowed to cool at room temperature. Endogenous peroxidase was blocked by $0.3 \% \mathrm{H}_{2} \mathrm{O}_{2}$ /methanol. The slides were incubated at $4{ }^{\circ} \mathrm{C}$ overnight with primary antibodies and reacted with EnVision + system HRP-labelled polymer (DAKO Japan Inc., Bunkyo-ku, Tokyo) as secondary antibody for $30 \mathrm{~min}$ at room temperature. Specific antigen-antibody reactions were visualised with $0.2 \%$ diaminobenzine tetrahydrochloride and hydrogen peroxide, and counterstained with Mayer haematoxylin. For each antibody, negative control studies were performed without the primary antibody. No significant staining was observed in the negative control sections. As positive control, formalin-fixed paraffin-embedded tissue microarrays from 20 ovarian serous adenocarcinomas were stained. Ovarian serous adenocarcinomas were known to be stained previously by all antibodies ( $\mathrm{Bu}$ et al, 2011; Yamamoto et al, 2011).

Immunoreactivity was scored according to intensity as negative $(-)$, moderate $(1+)$ or strong $(2+)$. If cases had $2+$ and $>50 \%$ of immunoreactive components, they were defined as high expression. Cases without high expression were defined as low expression. Two observers independently evaluated and interpreted the results of immunohistochemical staining without knowledge of the clinical data of each patient. In the interpretation of immunohistochemistry, any discrepancies between the two observers were resolved by discussion, and using a multiviewer microscope.

Cell lines and culture conditions. Ovarian cancer cell line derived from clear cell carcinoma, KK (Sasa et al, 1993), was used in this study. These cell lines were grown as monolayer cultures in RPMI-1640 (Life Technologies, Grand Island, NY, USA) + GlutmaxTM-I (Invitrogen Japan KK, Tokyo, Japan) medium supplemented with $10 \%$ foetal bovine serum (Invitrogen Japan KK), $100 \mathrm{U}$ penicillin per $\mathrm{ml}$, and $100 \mathrm{mg}$ streptomycin per $\mathrm{ml}$ (Invitrogen Japan KK) in a humidified atmosphere of $5 \% \mathrm{CO}_{2}$ at $37^{\circ} \mathrm{C}$, and routinely tested for mycoplasma infection.

Transient transfection. Nonspecific control siRNA, XIAP-specific siRNA (Signal Science XIAP siRNA, \#6446) and XIAP-specific siRNA II (Signal Science XIAP siRNA, \#6550) were purchased from Cell Signaling Technology. KK cells cultured in $3.5 \mathrm{~cm}$ plates were transfected with $107 \mathrm{~nm}$ of XIAP siRNA or XIAP siRNA II and control siRNA using Lipofectamine 2000 (Invitrogen Japan $\mathrm{KK}$ ) according to the manufacturer's specifications. X-chromosome-linked inhibitor of apoptosis knockdown was confirmed by western blot analysis in all the experiments. Names of the transfected cells using nonspecific control siRNA, XIAP-specific siRNA and XIAP siRNA II were determined as KK-C, KK-I and KK-II, respectively.

Cell proliferation and cytotoxicity assay. Cisplatin was obtained from Bristol Meier's Squib Oncology (Tokyo, Japan). KK-C, KK-I and KK-II were seeded onto 96-well plates at approximately $1 \times 10^{4}$ or $4 \times 10^{4}$ cells cm ${ }^{-2}$ for cytotoxicity assays after $24 \mathrm{~h}$ from the treatment at different cisplatin concentrations $(0,10,20$ and $30 \mu \mathrm{M})$. Cell viability was determined by MTT method using Tetra Color One (Seikagaku Corporation, Chiyoda-ku, Japan) according to the manufacturer's instructions.

Preparation of cell lysate for western blot analysis. Protein lysates were extracted in RIPA buffer (Wako Pure Chemical Industries Ltd, Osaka, Japan) according to the manufacturer's instructions. Protein concentrations were determined by Bradford assay (Bio-Rad Laboratories, Hercules, CA, USA). After electrophoresis of $10 \mu \mathrm{g}$ cytosolic fractions loaded onto Mini-PROTEIN TGXTM gel (Bio-Rad Laboratories), proteins were transferred to PVDF membranes using Trans-Blot Turbo Transfer System Transfer Pack (Bio-Rad Laboratories). Subsequently, the membranes were blocked for $1 \mathrm{~h}$ in 4\% BSA, and incubated overnight at $4{ }^{\circ} \mathrm{C}$ in primary antibodies. The following antibodies and concentrations were used: 1 out of 2000 rabbit anti-XIAP (Cell Signaling Technology), 1 out of 1000 rabbit monoclonal antibody for phospho-Akt (p-Akt; Ser473, Cell Signaling Technology), 1 out of 1000 rabbit monoclonal antibody for Bcl-XL (54H6, Cell Signaling Technology), 1 out of 1000 CONFIRM anti-total c-MET (SP44) rabbit monoclonal antibody for C-Met (Ventana Medical Systems, Tucson, AZ, USA), 1 out of 1000 rabbit monoclonal antibody for PTEN (138G6, Cell Signaling Technology) and 1 out of 5000 rabbit $\beta$-actin (Cell Signaling Technology). After washes with TBS-T, membranes were incubated for $1 \mathrm{~h}$ at room temperature using horseradish peroxidase-conjugated anti-rabbit secondary antibody (Cell Signaling Technology), and were visualised using the ECL detection system (GE Healthcare UK Ltd, Buckinghamshire, England) by a LAS-3000 imaging system (Fujifilm, Minato-ku, Tokyo). Protein expression was determined 
densitometrically and normalised against $\beta$-actin expression using the software Multi Gauge version 3.1 (Fujifilm).

Statistical analysis. The Stat View software ver.5.0 (SAS Institution Inc., Cary, NC, USA) was used for statistical analysis. Progression-free survival (PFS) was defined as the interval between the primary surgery and death or the date of progression disease. Overall survival was defined as the interval between the primary surgery and death. Staging was performed according to FIGO system. Performance status (PS) was evaluated by WHO criteria. Response rate was evaluated by using Response Evaluation Criteria in Solid Tumours (RECIST) criteria (Therasse et al, 2000). The $\chi^{2}$-test, Fisher's exact test and Mann-Whitney $U$-test were used to evaluate clinical significance of protein expression in clinicopathological parameters. Progression-free survival and OS curves were generated using the method of Kaplan-Meier. Comparisons of the survival distribution were made with log-rank test. Cox proportional hazards model was used for multivariate analysis of PFS and OS. All experiments were repeated independently at least four times. All values are presented as mean \pm s.d. Statistical significance between two groups was determined by use of a two-tailed $t$-test. Statistical significance was defined as a $P<0.05$.

\section{RESULTS}

Patients' characteristics and XIAP expression. A total of 90 cases with CCC were enrolled in this study. Median age of the patients was 52 years (range 35-72). FIGO stage distribution was as follows: 46 cases $(51 \%)$ in stage I, 9 cases $(10 \%)$ in stage II, 31 cases $(34 \%)$ in stage III and 4 cases (5\%) in stage IV. Ten cases $(11 \%)$ had $<1 \mathrm{~cm}$ residual tumours and 17 cases $(19 \%)$ had $>1 \mathrm{~cm}$ residual tumours. Eighty-six cases (96\%) underwent platinum-based chemotherapy as postoperative primary chemotherapy. Four cases with stage I disease refused to receive chemotherapy, despite physicians' recommendation. Distribution of XIAP immunoreactivity according to clinicopathological characteristics was shown in Table 1. X-chromosome-linked inhibitor of apoptosis expression was not influenced by age at diagnosis, WHO PS, FIGO stage and residual tumour diameter. Immunohistochemically, high expression levels of XIAP, c-Met, phospho-Akt and Bcl-XL were observed in 30 (33\%), 31 (34\%), $23(26 \%)$ and 33 (37\%), respectively. Representative staining of these proteins were shown in Supplementary Figure 1. The correlation of expression levels of c-Met, p-Akt and Bcl-XL in CCC tissues according to XIAP expression was also summarised in Table 1. High expression of XIAP was correlated with high expression of c-Met $(P<0.01)$ and Bcl-XL $(P<0.01)$. However, there was no significant association between expression levels of phospho-Akt and XIAP $(P=0.23)$.

XIAP expression in stage I clear cell adenocarcinoma of the ovary. Among 46 cases with stage I disease, there were no significant differences of age, physical status, FIGO stage and delivery of chemotherapy according to XIAP expression (Supplementary Table S1). In 46 cases with stage I disease, there were no statistical differences of PFS $(P=0.22$, Supplementary Figure $2 \mathrm{~A})$ and $\mathrm{OS}(P=0.99$, Supplementary Figure $2 \mathrm{~B})$ according to XIAP expression. In multivariate analysis for PFS and OS using variables of age, peritoneal cytology, completion of surgical staging and XIAP expression, high expression of XIAP was not identified as a prognostic factor for PFS $(P=0.29)$ and OS $(P=0.99)$.

XIAP expression in stages II-IV clear cell adenocarcinoma of the ovary. Expression levels of XIAP, c-Met, phospho-Akt and Bcl-XL according to response of primary chemotherapy were assessable in 27 patients who had measurable disease. All cases received platinum-based chemotherapy after primary surgery. High XIAP expression was significantly correlated with response
Table 1. Distribution of XIAP immunoreactivity according to clinicopathological characteristics in 90 patients with clear cell carcinoma of the ovary

\begin{tabular}{|c|c|c|c|c|}
\hline $\begin{array}{l}\text { Clinicopathological } \\
\text { variables }\end{array}$ & $\begin{array}{c}\text { Number } \\
(\%)\end{array}$ & $\begin{array}{l}\text { XIAP } \\
\text { high }\end{array}$ & $\begin{array}{l}\text { XIAP } \\
\text { low }\end{array}$ & $P$-value \\
\hline \multicolumn{5}{|c|}{ Age at diagnosis (years) } \\
\hline $\begin{array}{l}<50 \\
\geqslant 50\end{array}$ & $\begin{array}{l}35(39 \%) \\
55(61 \%)\end{array}$ & $\begin{array}{l}15(50 \%) \\
15(50 \%)\end{array}$ & $\begin{array}{l}20(33 \%) \\
40(67 \%)\end{array}$ & 0.13 \\
\hline
\end{tabular}

WHO performance status

\begin{tabular}{|l|c|c|c|c|}
\hline $0 / 1$ & $86(96 \%)$ & $28(93 \%)$ & $58(97 \%)$ & 0.47 \\
$\geqslant 2$ & $4(4 \%)$ & $2(7 \%)$ & $2(3 \%)$ & \\
\hline
\end{tabular}

FIGO stage

\begin{tabular}{|l|r|c|c|c|}
\hline I & $46(51 \%)$ & $12(40 \%)$ & $34(57 \%)$ & 0.26 \\
III & $9(10 \%)$ & $2(7 \%)$ & $7(12 \%)$ & \\
IV & $31(35 \%)$ & $14(46 \%)$ & $17(28 \%)$ & \\
& $4(4 \%)$ & $2(7 \%)$ & $2(3 \%)$ & \\
\hline
\end{tabular}

Residual tumour diameter

\begin{tabular}{|l|r|r|r|r|}
\hline $\begin{array}{l}\text { None } \\
\leqslant 1 \mathrm{~cm}\end{array}$ & $\begin{array}{r}63(70 \%) \\
10(11 \%)\end{array}$ & $\begin{array}{r}19(63 \%) \\
4(14 \%)\end{array}$ & $44(73 \%)$ & 0.62 \\
$71 \mathrm{~cm}(10 \%)$ & \\
\hline c-Met & $17(23 \%)$ & $10(17 \%)$ & \\
\hline High & $31(34 \%)$ & $16(53 \%)$ & $15(25 \%)$ & $<0.01$ \\
Low & $59(66 \%)$ & $14(47 \%)$ & $45(75 \%)$ & \\
\hline p-Akt & $23(26 \%)$ & $10(33 \%)$ & $13(22 \%)$ & 0.23 \\
\hline High & $67(74 \%)$ & $20(67 \%)$ & $47(78 \%)$ & \\
\hline
\end{tabular}

$\mathrm{Bcl}-\mathrm{XL}$

\begin{tabular}{|l|l|l|l|l|}
\hline High & $33(37 \%)$ & $17(57 \%)$ & $16(27 \%)$ & $<0.01$ \\
\hline Low & $57(63 \%)$ & $13(43 \%)$ & $44(73 \%)$ & \\
\hline
\end{tabular}

Abbreviations: $\mathrm{FIGO}=$ International Federation of Obstetrics and Gynecology; $\mathrm{WHO}=$ World Health Organisation; XIAP =X-chromosome-linked inhibitor of apoptosis.

to primary chemotherapy in CCC patients (Table 2). Significantly more cases of responders had low expression of XIAP compared with non-responders ( $90 \%$ vs 35\%, $P<0.01$ ). Expression levels of c-Met, phospho-Akt, and Bcl-XL were not related with response to chemotherapy.

Among 44 cases with stages II-IV tumours, high XIAP expression was observed 18 cases (Supplementary Table S2). There were no statistical differences of XIAP expression according to age, WHO physical status, FIGO stage and residual tumours after primary surgery. There was a significant difference of PFS according to XIAP expression $(P=0.02$, Figure $1 \mathrm{~A})$, however, significant difference was not observed in OS $(P=0.07$, Figure $1 \mathrm{~B})$. In univariate analysis, there were no significant differences of PFS and OS according to expression of c-Met, phospho-Akt and Bcl-XL. Multivariate analysis for PFS and OS in 44 cases was shown in Table 3. In addition to residual tumour diameter, XIAP expression was identified as an independent prognostic factor for PFS (hazard ratio $=2.94, P=0.02$ ) and $\mathrm{OS}$ (hazard ratio $=2.70, P=0.04$ ).

Downregulation of XIAP by siRNA and sensitivity to cisplatin. Further, we investigated whether XIAP downregulation by siRNA could increase sensitivity to cisplatin in KK cells, which were derived from human ovarian clear cell carcinoma. First, XIAP expression ratio compared with no transfection was $73.1 \pm 12.7 \%$ 
Table 2. Expression levels of XIAP, c-Met, phospho-Akt and Bcl-XL according to response of primary chemotherapy in 27 patients with evaluable disease

\begin{tabular}{|c|c|c|c|c|c|}
\hline Proteins & Expression level & $\begin{array}{l}\text { Number of } \\
\text { the patients }\end{array}$ & $\begin{array}{c}\text { Responders }^{a} \\
(n=10)\end{array}$ & $\begin{array}{c}\text { Non-responders }{ }^{b} \\
(n=17)\end{array}$ & $P$-value \\
\hline XIAP & $\begin{array}{l}\text { High } \\
\text { Low }\end{array}$ & $\begin{array}{l}12 \\
15\end{array}$ & $\begin{array}{l}1(10 \%) \\
9(90 \%)\end{array}$ & $\begin{array}{r}11(65 \%) \\
6(35 \%)\end{array}$ & 0.02 \\
\hline c-Met & $\begin{array}{l}\text { High } \\
\text { Low }\end{array}$ & $\begin{array}{l}11 \\
16\end{array}$ & $\begin{array}{l}2(20 \%) \\
8(80 \%)\end{array}$ & $\begin{array}{l}9(53 \%) \\
8(47 \%)\end{array}$ & 0.20 \\
\hline p-Akt & $\begin{array}{l}\text { High } \\
\text { Low }\end{array}$ & $\begin{array}{r}6 \\
21\end{array}$ & $\begin{array}{c}0(0 \%) \\
10(100 \%)\end{array}$ & $\begin{array}{r}6 \text { (35\%) } \\
11 \text { (65\%) }\end{array}$ & 0.10 \\
\hline $\mathrm{Bcl}-\mathrm{XL}$ & $\begin{array}{l}\text { High } \\
\text { Low }\end{array}$ & $\begin{array}{l}10 \\
17 \\
\end{array}$ & $\begin{array}{l}2(20 \%) \\
8(80 \%) \\
\end{array}$ & $\begin{array}{l}8(47 \%) \\
9(53 \%) \\
\end{array}$ & 0.32 \\
\hline
\end{tabular}
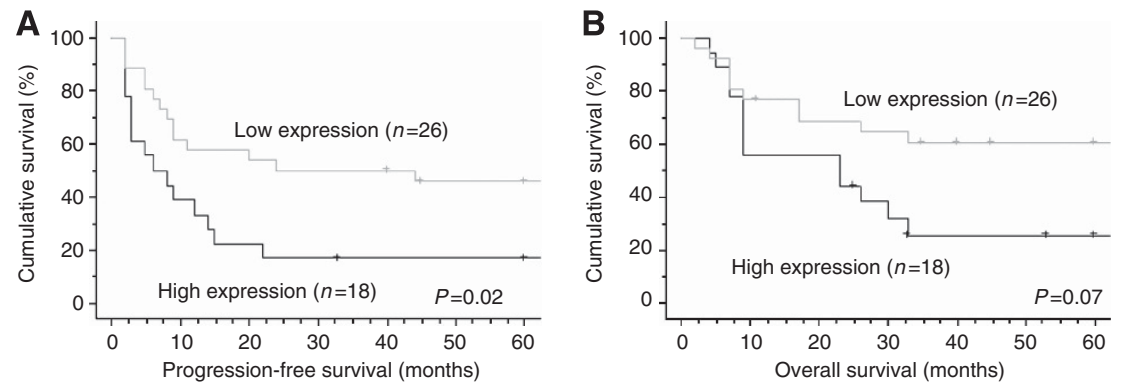

Figure 1. Progression-free survival (PFS) and overall survival (OS) curves of the patients with stages II-IV clear cell carcinoma of the ovary according to XIAP expression. (A) Progression-free survival curves of the patients. The patients with high expression of XIAP had significantly worse PFS $(P=0.02)$. (B) Overall survival curves of the patients. Although high expression of XIAP was related with poor survival, significant difference was not observed in two groups $(P=0.07)$.

Table 3. Multivariate analysis for progression-free survival and overall survival in 44 cases with stages II-IV ovarian clear cell carcinomas

\begin{tabular}{|c|c|c|c|c|c|c|c|}
\hline \multirow{3}{*}{$\begin{array}{l}\text { Variables } \\
\text { Age }\end{array}$} & \multirow[b]{3}{*}{$\leqslant 50$ vs $>50$} & \multicolumn{3}{|c|}{ Progression-free survival } & \multicolumn{3}{|c|}{ Overall survival } \\
\hline & & \multicolumn{2}{|c|}{ Hazard ratio $(95 \% \mathrm{Cl})$} & \multirow{2}{*}{$\begin{array}{r}\boldsymbol{P} \text {-value } \\
0.51\end{array}$} & \multicolumn{2}{|c|}{ Hazard ratio $(95 \% \mathrm{Cl})$} & \multirow{2}{*}{$\begin{array}{c}\boldsymbol{P} \text {-value } \\
0.23\end{array}$} \\
\hline & & 0.75 & $(0.32-1.76)$ & & 0.55 & $(0.20-1.48)$ & \\
\hline WHO performance status & $0 / 1$ vs $\geqslant 2$ & 0.74 & $(0.14-3.79)$ & 0.71 & 0.58 & $(0.11-2.95)$ & 0.51 \\
\hline FIGO stage & II vs III/IV & 0.58 & $(0.19-1.77)$ & 0.37 & 0.60 & $(0.16-2.22)$ & 0.44 \\
\hline Residual tumour diameter & $>1 \mathrm{~cm}$ vs $\leqslant 1 \mathrm{~cm}$ & 3.48 & $(1.40-8.62)$ & $<0.01$ & 5.35 & $(1.98-15.0)$ & $<0.01$ \\
\hline XIAP expression & High vs low & 2.94 & $(1.22-7.09)$ & 0.02 & 2.70 & $(1.02-7.16)$ & 0.04 \\
\hline
\end{tabular}

in KK-C, $20.6 \pm 3.9 \%$ in KK-I and $19.5 \pm 6.7 \%$ in KK-II. $\mathrm{X}$-chromosome-linked inhibitor of apoptosis expression was significantly downregulated in both KK-I and KK-II in comparison with KK-C (Figure 2A). Expression levels of c-Met, Bcl-XL and PTEN were similar in those cells, however, p-Akt expression was slightly decreased in KK-I and KK-II cells compared with KK-C: $62.9 \pm 11.0 \%$ in KK-I, $64.5 \pm 4.6 \%$ in KK-II. (Figure 2A). Next, these cells were treated with cisplatin for $24 \mathrm{~h}$ at a dose of $10 \mu \mathrm{M}$. Expression levels of cleaved caspase- 3 and cleaved PARP increased in both KK-I and KK-II cells (Figure 2B). Further, these cells were treated with cisplatin for $24 \mathrm{~h}$ in different dose $(0,10,20$ and $30 \mu \mathrm{M})$. Apoptotic ratios of KK-I and KK-II were significantly higher compared with that of $\mathrm{KK}-\mathrm{C}$ at each concentration in a dose-dependent manner (Figure 2C).

\section{DISCUSSION}

Overall positive rate of XIAP in CCC was 33\% in the present analysis. Previous report showed that serous adenocarcinoma of the ovary had approximately $85 \%$ positive rate of XIAP ( $\mathrm{Bu}$ et al, 2011). Twenty samples used for positive control of XIAP were all judged as high expression of XIAP, implying that positive rate of XIAP in CCC was lower than that in serous ovarian cancers. Most of serous ovarian cancer had overexpression of p53; however, CCC had less involvement of p53 alteration and p53-independent mechanisms for chemoresistance in CCC was suggested (Eltabbakh et al, 2006). In this study, XIAP expression was not influenced by age at diagnosis, WHO PS, FIGO stage and residual tumour 

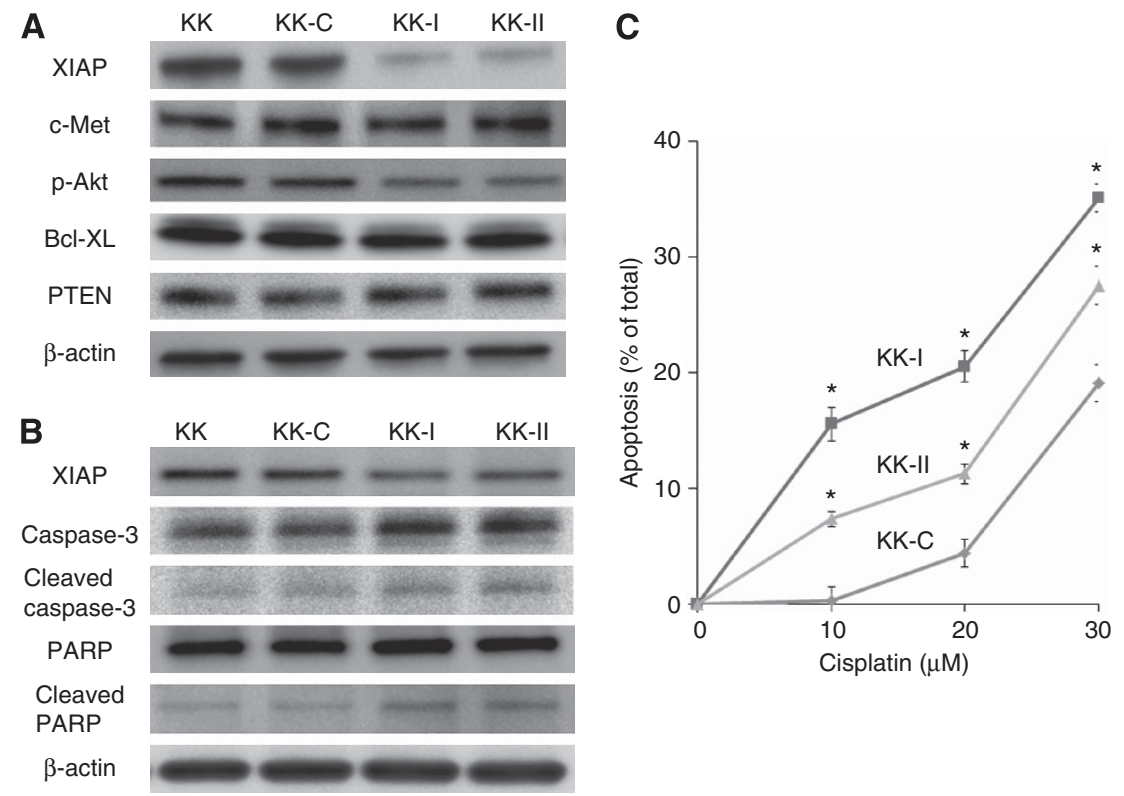

Figure 2. Downregulation of XIAP by transfection with XIAP siRNA and sensitivity to cisplatin in vitro. (A) Clear cell carcinoma cell line, KK, was transfected with nonspecific siRNA (KK-C), XIAP-specific siRNA I (KK-I) and XIAP-specific siRNA II (KK-II). Expression ratio of XIAP protein compared with KK cells without transfection was as follows: $73.14 \pm 12.7 \%$ in KK-C, $20.6 \pm 3.94 \%$ in KK-I and $19.54 \pm 6.67 \%$ in KK-II, respectively. Phospho-Akt expression was decreased in KK-I and KK-II cells compared with KK-C: $62.9 \pm 11.0 \%$ in KK-I, $64.5 \pm 4.6 \%$ in KK-II. (B) After transfection, these cells were treated with for $24 \mathrm{~h}$ at a dose of $10 \mu \mathrm{m}$. Expression levels of cleaved caspase- 3 and cleaved PARP increased in both KK-I and KK-II cells compared with KK or KK-C. (C) Apoptosis fractions induced by 24-h treatment of cisplatin in KK-C, KK-I and KK-II were shown. Ratio of apoptotic fraction was higher in KK-I and KK-II compared with that of KK-C at each concentration. The data represented the mean \pm s.d. of at least four times. ${ }^{\star} P<0.01$.

diameter. However, increased XIAP expression was significantly related with resistance to platinum-based chemotherapy and worse prognosis of CCC disease. To our knowledge, there have been no reports evaluating XIAP expression in a series of consecutive cases of ovarian clear cell adenocarcinomas. X-chromosome-linked inhibitor of apoptosis expression has been recognised as a predictor of platinum resistance in several cancers (Schimmer et al, 2006; Yang et al, 2012). In addition, high XIAP expression was related with worse prognosis in human neoplasms (Tamm et al, 2004a, b; Mizutani et al, 2007). Recently, inhibition of XIAP has been recognised as a potential target of cancer therapy. Downregulation of XIAP by transfection with XIAP siRNA resulted in decreased phospho-Akt expression, and increased chemosensitivity to anticancer drugs (Jiang et al, 2012). X-chromosome-linked inhibitor of apoptosis has been shown to act as an E3 ubiquitin ligase for PTEN and to promote Akt activity (Van Themsche et al, 2009). However, PTEN expression level was not affected in the present system, suggesting another signalling pathway to activate Akt signalling, which is not related with PTEN ubiquitination. In addition, XIAP downregulation by a small-molecule inhibitor abrogated XIAP/procaspase-9 interaction, and decreased cell viability that was resistant to anticancer agents (Aird et al, 2010). This study revealed that XIAP overexpression resulted in chemoresistance against platinum-based chemotherapy and worse PFS of CCC patients. In the present system, downregulation of XIAP by transfection with XIAP siRNA increased sensitivity to cisplatin in CC through downregulation of p-Akt. Although further study is needed, XIAP expression is identified as one of the fundamental mechanisms as to how CCC showed intrinsic chemoresistance.

Previous immunochemical analysis for ovarian cancers mainly consisting of serous adenocarcinomas revealed that c-Met expression was correlated with expression levels of phospho-Akt-Ser 473, XIAP and Bcl-XL (Bu et al, 2011). Significant correlation of XIAP with c-Met expression observed in this study suggested that XIAP was regulated by $\mathrm{HGF} / \mathrm{c}-\mathrm{Met}$ in CCC. In our study, XIAP expression was not related with phospho-Akt (Ser 473). This may be simply explained by a small sample number; however, there may be another HGF/c-Met/XIAP pathway that was not through activation of phospho-Akt at Ser 473.

In a report including a large case series of advanced-staged CCC, residual tumour was the only independent prognostic factor, and adjuvant chemotherapy was not identified as a prognostic factor (Takano et al, 2006). Multivariate analysis in stages II-IV CCC showed that XIAP expression was an independent prognostic factor for PFS and OS in CCC, in addition to residual tumour diameter. It was revealed that high expression of XIAP was significantly correlated with resistance to primary chemotherapy, and led to worse prognosis in CCC. So, inhibition of XIAP expression using a c-Met inhibitor (Appleman, 2011) or a XIAP inhibitor (Kamsteeg et al, 2003) could be a novel strategy for the treatment of CCC.

The limitation of this study included a retrospective investigation and a single-institutional analysis. Also, the results obtained by this study could potentially have a bias such as selection bias, and further prospective investigation is needed to confirm the impact of XIAP expression upon prognoses of CCC patients. Nevertheless, XIAP could have an important role in chemoresistant phenotype in CCC, and high expression of XIAP was identified as an independent prognostic factor in stages II-IV CCC tumours. $\mathrm{X}$-chromosome-linked inhibitor of apoptosis should be further evaluated as one of promising targets in chemotherapy for CCC.

\section{CONFLICT OF INTEREST}

The authors declare no conflict of interest. 


\section{REFERENCES}

Aird KM, Ghanayem RB, Peplinski S, Lyerly HK, Devi GR (2010) X-linked inhibitor of apoptosis protein inhibits apoptosis in inflammatory breast cancer cells with acquired resistance to an ErbB1/2 tyrosine kinase inhibitor. Mol Cancer Ther 9: 1432-1442.

Appleman LJ (2011) MET signaling pathway: a rational target for cancer therapy. J Clin Oncol 29: 4837-4838.

Asselin E, Mills GB, Tsang BK (2001) XIAP regulates Akt activity and caspase-3-dependent cleavage during cisplatin-induced apoptosis in human ovarian epithelial cancer cells. Cancer Res 61: 1862-1868.

Bu R, Uddin S, Bavi P, Hussain AR, Al-Dayel F, Ghourab S, Ahmed M, Al-Kuraya KS (2011) HGF/c-Met pathway has a prominent role in mediating antiapoptotic signals through AKT in epithelial ovarian carcinoma. Lab Invest 91: 124-137.

Eltabbakh GH, Mount SL, Beatty B, Simmons-Arnold L, Cooper K (2006) Clinical and molecular differences between clear cell and papillary serous ovarian carcinoma. J Surg Oncol 93: 379-386.

Jiang C, Yi XP, Shen H, Li YX (2012) Targeting X-linked inhibitor of apoptosis protein inhibits pancreatic cancer cell growth through p-Akt depletion. World J Gastroenterol 18: 2956-2965.

Kamsteeg M, Rutherford T, Sapi E, Hanczaruk B, Shahabi S, Flick M, Brown D, Mor G (2003) Phenoxodiol-an isoflavone analog-induces apoptosis in chemoresistant ovarian cancer cells. Oncogene 22: 2611-2620.

Knudsen BS, Zhao P, Resau J, Cottingham S, Gherardi E, Xu E, Berghuis B, Daugherty J, Grabinski T, Toro J, Giambernardi T, Skinner RS, Gross M, Hudson E, Kort E, Lengyel E, Ventura A, West RA, Xie Q, Hay R, Woude GV, Cao B (2009) A novel multipurpose monoclonal antibody for evaluating human c-Met expression in preclinical and clinical settings. Appl Immunohistochem Mol Morphol 17: 57-67.

Lacasse EC, Baird S, Korneluk RG, MacKenzie AE (1998) The inhibitors of apoptosis (IAPs) and their emerging role in cancer. Oncogene 17: 3247-3259.

Li J, Feng Q, Kim JM, Schneiderman D, Liston P, Li M, Vanderhyden B, Faught W, Fung MF, Senterman M, Korneluk RG, Tsang BK (2001) Human ovarian cancer and cisplatin resistance: possible role of inhibitor of apoptosis proteins. Endocrinology 142: 370-380.

Ma JJ, Chen BL, Xin XY (2009) XIAP gene downregulation by small interfering RNA inhibits proliferation, induces apoptosis, and reverses the cisplatin resistance of ovarian carcinoma. Eur J Obstet Gynecol Reprod Biol 146: $222-226$

Mizutani Y, Nakanishi H, Li YN, Matsubara H, Yamamoto K, Sato N, Shiraishi T, Nakamura T, Mikami K, Okihara K, Takaha N, Ukimura O, Kawauchi A, Nonomura N, Bonavida B, Miki T (2007) Overexpression of XIAP expression in renal cell carcinoma predicts a worse prognosis. Int J Oncol 30: 919-925.

Sasa H, Ishii K, Hirata J, Kikuchi Y, Nagata I, Kawai T, Senoo A, Sugita M, Sugishita T, Tenjin Y (1993) Establishment and characterization of a CA-125-producing human ovarian clear cell carcinoma cell line. Hum Cell 6: $279-286$.

Sasaki H, Sheng Y, Kotsuji F, Tsang BK (2000) Downregulation of X-linked inhibitor of apoptosis protein induces apoptosis in chemoresistant human ovarian cancer cells. Cancer Res 60: 5659-5666.

Schimmer AD, Dalili S, Batey RA, Riedl SJ (2006) Targeting XIAP for the treatment of malignancy. Cell Death Differ 13: 179-188.

Serov SF, Scully RE, Sobin LH (1973) International histologic classification of tumors. In No.9. Histologic Typing of Ovarian Tumors. World Health Organization: Geneva.

Sugiyama T, Kamura T, Kigawa J, Terakawa N, Kikuchi Y, Kita T, Suzuki M, Sato I, Taguchi K (2000) Clinical characteristics of clear cell carcinoma of the ovary. Cancer 88: 2584-2587.
Takano M, Kikuchi Y, Yaegashi N, Kuzuya K, Ueki M, Tsuda H, Suzuki M, Kigawa J, Takeuchi S, Tsuda H, Moriya T, Sugiyama T (2006) Clear cell carcinoma of the ovary: a retrospective multicentre experience of 254 patients with complete surgical staging. Br J Cancer 94: 1369-1374.

Takano M, Sugiyama T, Yaegashi N, Sakuma M, Suzuki M, Saga Y, Kuzuya K, Kigawa J, Shimada M, Tsuda H, Moriya T, Yoshizaki A, Kita T, Kikuchi Y (2008) Low response rate of second-line chemotherapy for recurrent or refractory clear cell carcinoma of the ovary: a retrospective Japan Clear Cell Carcinoma Study. Int J Gynecol Cancer 18: 937-942.

Takano M, Tsuda H, Sugiyama T (2012) Clear cell carcinoma of the ovary: is there a role of histology-specific treatment? J Exp Clin Cancer Res 31: 53.

Takano M, Goto T, Kato M, Sasaki N, Miyamoto M, Furuya K (2013) Short response duration even in responders to chemotherapy using conventional cytotoxic agents in recurrent or refractory clear cell carcinomas of the ovary. Int J Clin Oncol 18: 556-557.

Tamm I, Kornblau SM, Segall H, Krajewski S, Welsh K, Kitada S, Scudiero DA, Tudor G, Qui YH, Monks A, Andreeff M, Reed JC (2000) Expression and prognostic significance of IAP-family genes in human cancers and myeloid leukemias. Clin Cancer Res 6: 1796-1803.

Tamm I, Richter S, Oltersdorf D, Creutzig U, Harbott J, Scholz F, Karawajew L, Ludwig WD, Wuchter C (2004a) High expression levels of $\mathrm{x}$-linked inhibitor of apoptosis protein and survivin correlate with poor overall survival in childhood de novo acute myeloid leukemia. Clin Cancer Res 10: 3737-3744.

Tamm I, Richter S, Scholz F, Schmelz K, Oltersdorf D, Karawajew L, Schoch C, Haferlach T, Ludwig WD, Wuchter C (2004b) XIAP expression correlates with monocytic differentiation in adult de novo AML: impact on prognosis. Hematol J 5: 489-495.

Therasse P, Arbuck SG, Eisenhauer EA, Wanders J, Kaplan RS, Rubinstein L, Verweij J, Van Glabbeke M, van Oosterom AT, Christian MC, Gwyther SG (2000) New guidelines to evaluate the response to treatment in solid tumors. European Organization for Research and Treatment of Cancer, National Cancer Institute of the United States, National Cancer Institute of Canada. J Natl Cancer Inst 92: 205-216.

Van Themsche C, Leblanc V, Parent S, Asselin E (2009) X-linked inhibitor of apoptosis protein (XIAP) regulates PTEN ubiquitination, content, and compartmentalization. J Biol Chem 284: 20462-20466.

Winter 3rd WE, Maxwell GL, Tian C, Carlson JW, Ozols RF, Rose PG, Markman M, Armstrong DK, Muggia F, McGuire WP. Gynecologic Oncology Group Study (2007) Prognostic factors for stage III epithelial ovarian cancer: a Gynecologic Oncology Group Study. J Clin Oncol 25: 3621-3627.

Yamamoto S, Tsuda H, Miyai K, Takano M, Tamai S, Matsubara O (2011) Gene amplification and protein overexpression of MET are common events in ovarian clear-cell adenocarcinoma: their roles in tumor progression and prognostication of the patient. Mod Pathol 24: 1146-1155.

Yang L, Cao Z, Yan H, Wood WC (2003) Coexistence of high levels of apoptotic signaling and inhibitor of apoptosis proteins in human tumor cells: implication for cancer specific therapy. Cancer Res 63: 6815-6824.

Yang XH, Feng ZE, Yan M, Hanada S, Zuo H, Yang CZ, Han ZG, Guo W, Chen WT, Zhang P (2012) XIAP is a predictor of cisplatin-based chemotherapy response and prognosis for patients with advanced head and neck cancer. PLoS One 7: e31601.

This work is published under the standard license to publish agreement. After 12 months the work will become freely available and the license terms will switch to a Creative Commons AttributionNonCommercial-Share Alike 3.0 Unported License.

Supplementary Information accompanies this paper on British Journal of Cancer website (http://www.nature.com/bjc) 